This is a post-print version of the article 'Moro, F.R. (2018). Divergence in heritage Ambon Malay in the Netherlands: The role of social-psychological factors. International Journal of Bilingualism, 22(4), 395-411.', which is online available: https://doi.org/10.1177/1367006918762155

\title{
Divergence in heritage Ambon Malay in the Netherlands: the role of social-psychological factors - Francesca Moro
}

\begin{abstract}
Aims and Objectives/Purpose/Research Questions

This article examines the role of social-psychological factors in the development of heritage Ambon Malay in the Netherlands. More specifically, it aims to answer the question: Can socialpsychological factors account for the different frequency of Dutch-like structures among heritage speakers?

\section{Design/Methodology/Approach}

Data from 32 Ambon Malay heritage speakers and 27 Ambon Malay homeland speakers were collected by means of video stimuli and a sociolinguistic interview.

\section{Data and Analysis}

The database provides six linguistic variables and three social-psychological factors. The linguistic variables are: the pre-verbal marker $a d a$, the definite marker =nya, the double object construction, the prepositional phrase and adjectival phrase in resultative constructions, the prenominal order for the demonstrative itu and the numeral satu 'one'. The social-psychological factors are place where the speaker lives, onset of Dutch bilingualism, and attitude. The effect of the social-psychological factors on the linguistic variables was assessed using a multivariate general linear model.
\end{abstract}

\section{Findings/Conclusions}

The results show that place where the speaker lives is the best predictor. Heritage speakers living outside a Moluccan ward have a higher rate of Dutch-like features than speakers living inside a Moluccan ward. In some cases, sequential bilinguals are more innovative than simultaneous bilinguals. Finally, speakers with only a mild positive attitude toward the heritage language have a higher rate of Dutch-like features.

\section{Originality}

Unlike previous studies, this article does not test the role of social-psychological factors against self-ratings of heritage language proficiency, but it uses real language data.

\section{Significance/Implications}

The theoretical significance of this research is to bridge the gap between the sphere of language structure and the sphere of language use and language attitude. An additional value is in its finding that frequent use of the heritage language means higher rate of maintenance but also accelerated change.

Keywords: heritage language, Malay, Dutch, social factors, attitude, bilingualism

\section{Introduction}

This article examines the role of social-psychological factors in the development of Ambon Malay in the Netherlands, a heritage language spoken by Moluccan immigrants and their descendants (see the section Ambon Malay in the Netherlands). Due to the intense contact with Dutch, the dominant language of the country, and to the restricted domains of usage (typically the home), heritage Ambon Malay has come to diverge significantly from its homeland variety and has adopted a number of Dutch-like features (Tahitu, 1989; Huwaë, 1992; Aalberse \& Moro, 
2014; Moro, 2014, 2015, 2016, 2017; Moro \& Klamer, 2015; Moro \& Irizarri van Suchtelen, 2017; see also the section Structural features).

In the scenario approach to language contact, every linguistic change is seen as both structurally and socially embedded (Muysken, 2010, p. 272). The outcome of language contact is thus determined both by structural and social factors: structural factors, such as the typological profile of the two languages, supply the material for the change and determine the shape that the change is going to take; social factors determine the amount and the destination of the change (Croft, 2000; Muysken, 2010; Johanson, 2013). In heritage language communities, social factors are the main determinants of the variation observed among speakers. Some heritage speakers speak an acrolectal variety closer to the baseline, while others speak a basilectal variety more divergent from the baseline, with a range of possibilities along the continuum (Kondo-Brown 2003, p. 2; Polinsky \& Kagan, 2007, p. 371; for a more detailed discussion see section Socialpsychological factors).

The goal of this article is to contribute to this line of research by asking: Can socialpsychological factors account for the different frequency of Dutch-like features among heritage speakers? Unlike previous studies, the focus of this article is not on heritage language proficiency, but rather on heritage language structure. More specifically, this article brings together the sphere of language structure, which deals with the structural changes that the heritage variety has undergone, and the sphere of language use and language attitude. Using both a quantitative and qualitative approach, this article investigates whether social-psychological factors predict the frequency of use of certain Dutch-like structures in heritage Ambon Malay.

\section{Ambon Malay in the Netherlands}

Ambon Malay is a variety of Malay spoken in the Central Moluccas, in eastern Indonesia. Due to historical events, it is also spoken as heritage language in the Netherlands. After the Republic of Indonesia was proclaimed in 1945, the Dutch government dismantled its Royal Dutch-Indies Army, which was formed mainly by Moluccan soldiers. Political events forced the Dutch government to 'temporarily' bring the soldiers and their families (about 12.500 people) to the Netherlands. After their arrival, the Moluccans were housed in 34 camps spread all over the Netherlands. The camps were situated in rural and isolated areas of the country, where the Moluccans lived segregated until the 1960s. During the first period of residence, little effort was made by the Dutch and by the Moluccans to facilitate the integration process because both parties believed that the stay of the Moluccans in the Netherlands would be temporary

In the beginning of the 1960s, it became clear that the stay of the Moluccans would become permanent. Therefore, the Dutch government decided to close the camps and to move the Moluccans to newly built wards on the outskirts of small towns. The social consequence of this housing situation was that Moluccans living in a municipality with a Moluccan ward were less likely to have contact with the Dutch than those living in a municipality without a Moluccan ward (Veenman, 1994). Although the situation is changing, Vermeulen and Penninx (2000, p. 9) report that 'though they [the Moluccans] increasingly disperse from these areas, they are still the 
least likely of all six groups [Turks, Moroccans, Southern Europeans, Surinamese, Antilleans, and Moluccans] to be found in big cities'.

\section{Social-psychological factors: age of onset of bilingualism, generation, social network, and attitude}

In bilingual heritage communities, the emergence and development of linguistic change is usually related to factors such as age of onset of bilingualism (sequential vs. simultaneous) and parental language input (Montrul, 2008; Unsworth, Argyri, Cornips, Hulk, Sorace, \& Tsimpli, 2014). Montrul (2008) cites a number of studies showing that simultaneous bilinguals make more errors than sequential bilinguals, and (p. 115) concludes that 'incomplete acquisition appears to be more dramatic in simultaneous than in sequential bilingualism, due to the reduced amount of input received in one language while the language was not yet fully developed'. Parental language input is also an important predictor of linguistic innovations. For instance, Irizarri van Suchtelen (2014) shows that, although all Spanish heritage speakers in the Netherlands diverge considerably from their monolingual peers, heritage speakers with two Spanish speaking parents perform more native-like than heritage speakers who grew up with only one Spanish speaking parent and did not productively use Spanish in childhood.

Generation is yet another factor that correlates with language maintenance and language proficiency in heritage language communities (Silva-Corvalán, 1994; Hulsen, 2000). The heritage language has been found to decline with each generation, following the pattern G1 > G2 > G3. Generally speaking, first generation speakers are dominant in the heritage language, second generation speakers have relatively strong skills in both the heritage and the majority languages, whereas third generation speakers are dominant in the majority language; beyond the third generation, few heritage speakers retain a functional command of their language (Benmamoun et al., 2013, p. 79).

Social network structure has also proved to be a factor influencing the degree of language preservation and language ability in immigrant communities. Most of the findings demonstrate the territorially based networks enhance the frequency and the intensity of contact among the community members, which, in turn, favour language preservation (Wei, 1994; Wei et al., 2000; Chau, 2011). For instance, a comparison between two Chinese groups of families in Tyneside, England, - one with strong ties and affiliated to the True Jesus church, the other with weak ties and lacking a centralized institution- shows that the families of the first group have a higher level of language maintenance and language proficiency compared to the families in the second group (Wei et al., 2000). Another example is that provided by Chau (2011), who compares Cantonese heritage speakers in Amsterdam (an urban area), where a large community of Cantonese is present, to Cantonese heritage speakers in Venlo (a rural area), who are rather isolated. Heritage speakers in Amsterdam use Cantonese to a larger extent than the Cantonese heritage speakers in Venlo, because the former can share their experiences with their Cantonese speaking peers who live in the neighbourhood, whereas the latter do not have many Chinese peers. According to Chau (2011), the low exposure to Cantonese of Venlo heritage speakers accounts for the many 
deviations found in their speech (i.e., wrong use of nominal classifiers, inverted double object construction).

Other factors are attitude and ethnic identity (Kondo, 1997; Kondo-Brown, 2001; Noels, 2005). The studies of Kondo (1997) and Kondo-Brown (2001) found an association between levels of Japanese proficiency and factors such as Japanese language use at home, degree of family commitment to the heritage language, and attitude. By comparing heritage and nonheritage learners of German in Canada, Noels (2005) shows that heritage students tend to learn German because it is important for their identity and these heritage learners are also more likely to evaluate themselves as skilled in German when compared to learners without a heritage motivation. A serious weakness of these studies, however, is that the analysis is based on speakers' self-ratings of language proficiency (Kondo-Brown 2003, p. 15).

Although many studies report a positive interaction between language use and socialpsychological factors, this interaction is more complex than it first appears. Frequent heritage language use can entail a higher rate of maintenance but it can also entail a higher rate of innovations (or accelerated change). Maintaining one's heritage language does not necessarily mean maintaining the homeland-like variety of the heritage language. According to Schmid (2011), speakers who use the L1 and L2 frequently alongside each other may display accelerated signs of linguistic change, because the frequent use of both languages creates the condition for cross-linguistic influence. In her study on German immigrants in Canada and the Netherlands, Schmid (2011, p. 171) concludes that:

These findings suggest that change and deterioration of the L1 which may be witnessed among migrant populations may be determined by two opposite poles: speakers who do not use their L1 at all may experience some degree of 'atrophy', while those who live in a bilingual migrant community where L1 and L2 are used frequently alongside each other and mixed to some degree may find themselves sharing in a language with accelerated signs of contact induced change.

To conclude, although there is an increasing body of evidence showing that heritage speakers with a history of low exposure to or use of the heritage language exhibit divergent (less homeland-like) patterns, this is not always the case, as both infrequent and frequent use can accelerate on-going language change.

\section{The study: Social-psychological factors and linguistic divergence in heritage Ambon Malay}

The aim of this study is to investigate the association between the structural divergence in various areas of heritage Ambon Malay grammar and social-psychological factors in order to account for the variability observed in the heritage speaker population. The data on structural divergence are based on previous work on heritage Ambon Malay (Moro, 2014, 2016, 2017; Moro \& Klamer, 2015). 


\section{Methodology}

Two groups of speakers are tested in this study: a group of heritage speakers and a control group of homeland speakers, as laid out in Table 1.

Table 1: Information about the number, gender and age of the participants in the four groups.

\begin{tabular}{llllll}
\hline & & Total & Female & Male & Age (mean) \\
\hline Test group & Heritage Ambon Malay & 32 & 16 & 16 & 43.78 \\
Control group & Homeland Ambon Malay & 27 & 16 & 13 & 43.04 \\
\hline
\end{tabular}

The heritage speakers all acquired Ambon Malay from birth at home. The age of onset of acquisition of Dutch varies: 22 are simultaneous bilinguals (onset of Dutch bilingualism: birth); 10 are sequential bilinguals (onset of Dutch bilingualism: age five). The control group is formed by native speakers of Ambon Malay who currently live on Ambon or one of the surrounding islands.

All speakers performed the same three tasks: (i) a simultaneous oral description of a set of 14 videos, (ii) an oral description of a set of 68 short video-clips, and (iii) a sociolinguistic interview (for the complete list of videos, video-clips sand the sociolinguistic questions see Appendix 1, 2 and 3 in Moro, 2016). The speakers were coded for five social factors, as illustrated in Table 2:

Table 2: Coding of social factors

\begin{tabular}{lc}
\hline Generation & 3 point scale: coding \\
\hline Second generation & 3 \\
Generation $2.5^{1}$ & 2 \\
Third generation & 1 \\
\hline Place were the speaker grew up & 3 point scale: coding \\
\hline Moluccan camp & 3 \\
Moluccan ward & 2 \\
City (outside a Moluccan ward) & 1 \\
\hline Place were the speaker lives & 2 point scale: coding \\
\hline Moluccan ward & 2 \\
City (outside a Moluccan ward) & 1 \\
\hline Parental language input & 3 point scale: coding \\
\hline Mainly Ambon Malay & 2 \\
Ambon Malay and Dutch & 1 \\
Mainly Dutch & 2 point scale: coding \\
\hline Onset of Dutch bilingualism
\end{tabular}

\footnotetext{
${ }^{1}$ Speakers belonging to this generation have one parent form the first generation and the other parent from the second generation.
} 


\begin{tabular}{lc}
\hline $\begin{array}{l}\text { from age five (sequential bilingual) } \\
\text { from birth (simultaneous bilingual) }\end{array}$ & 2 \\
\hline Attitude & 1 \\
\hline Mild positive & 2 \\
(speakers who think that Ambon Malay is important but do & \\
not translate this into actual practice) & 1 \\
Strongly positive & \\
(speakers who think that Ambon Malay is important and are & \\
actively committed to Ambon Malay maintenance) & \\
\hline
\end{tabular}

These data were used for the analysis of social factors in the next section.

\section{Structural features}

The structures that will be considered here are those referred to as 'Dutch-like' or 'Dutchaligned' features in Moro (2016, p. 221). ${ }^{2}$ If homeland Ambon Malay has two options, A and B, and option B is also present in Dutch (e.g. a translation equivalent, or the same word order pattern, etc.), heritage speakers tend to use the Dutch-like feature (option B) more often. The Dutch-like features that will be discussed below are: the higher frequency of the pre-verbal marker $a d a$ 'EXIST', and of definite marker =nya 'DEF', the increase in the frequency of DO in give-constructions, and of PP and AP in resultative constructions; the higher frequency of the pre-nominal order for the demonstrative itu and the numeral satu 'one'.

The pre-verbal marker ada 'EXIST'. Ambon Malay does not mark tense, but it marks grammatical aspect analytically. Aspect marking is optional and the correct temporal interpretation of the utterance is often inferred from the (extra-) linguistic context. In Dutch, present and past tense marking is expressed by means of verbal inflection. Tense inflection and verbal agreement instantiate also the feature of finiteness, which is obligatorily marked in Dutch. The Ambon Malay pre-verbal marker ada mainly marks progressive aspect. the description of the 14 videos, $a d a$ is used much more frequently by heritage speakers $(13.75 \%)$ than by homeland speakers (3.43\%). The shift in temporal status and frequency of ada suggests a reanalysis of $a d a$ as a present-tense or finiteness marker due to the intense contact with Dutch, a language where tense and finiteness are obligatorily encoded on the verb.

The definite marker =nya. Ambon Malay nouns are not obligatorily marked for (in)definiteness. Unlike Ambon Malay, Dutch obligatorily expresses the category of (in)definiteness. The Ambon Malay enclitic =nya may occur on nouns to indicate definiteness. In the description of the 14 videos, =nya is used much more frequently by heritage speakers $(11.1 \%$ of already mentioned nouns) than by homeland speakers $(0.7 \%)$. The increase in the frequency of =nya suggests some heritage speakers use this form consistently to mark already mentioned nouns, following a pattern typical of Dutch.

\footnotetext{
${ }^{2}$ The differences in frequency among the heritage group and the homeland group are all statistically significant. The reader is referred to Moro (2016) for more a more detailed description of these studies.
} 
The Double Object construction in give-events. ${ }^{3}$ To express give-events, Ambon Malay allows both Prepositional Object (PO) constructions (e.g. John gives a book to Mary) and Double Object (DO) construction (e.g. John gave Mary a book). The use of the DO construction, however, is rare and mostly limited to constructions in which the Recipient argument is a pronoun (e.g. John gave her a book). Dutch also allows both constructions, PO constructions are more frequent in elicited data, while DO constructions are very frequent in corpora (Colleman \& Bernolet, 2012). Heritage speakers use DO constructions (11.28\%) significantly more than homeland speakers $(0.74 \%)$.

The Prepositional Phrase and the Adjectival Phrase constructions in resultative events. Both Ambon Malay and Dutch use various constructions to expression resultative events. Ambon Malay prefers serial verb constructions (SVC) (e.g. She breaks a stick becomes two), while Dutch prefers verb particles (e.g. She cuts off a branch). However, both languages also allow resultative preposition phrases (PP) (e.g. She breaks a stick in two) and adjectival phrases (AP) (e.g. She hits a vase broken). When describing the ten 'cut and break' video-clips, heritage speakers of Ambon Malay use resultative PPs and APs, the constructions shared with Dutch, significantly more than homeland speakers, who prefer SVC. The data are summarized in Figure 2.

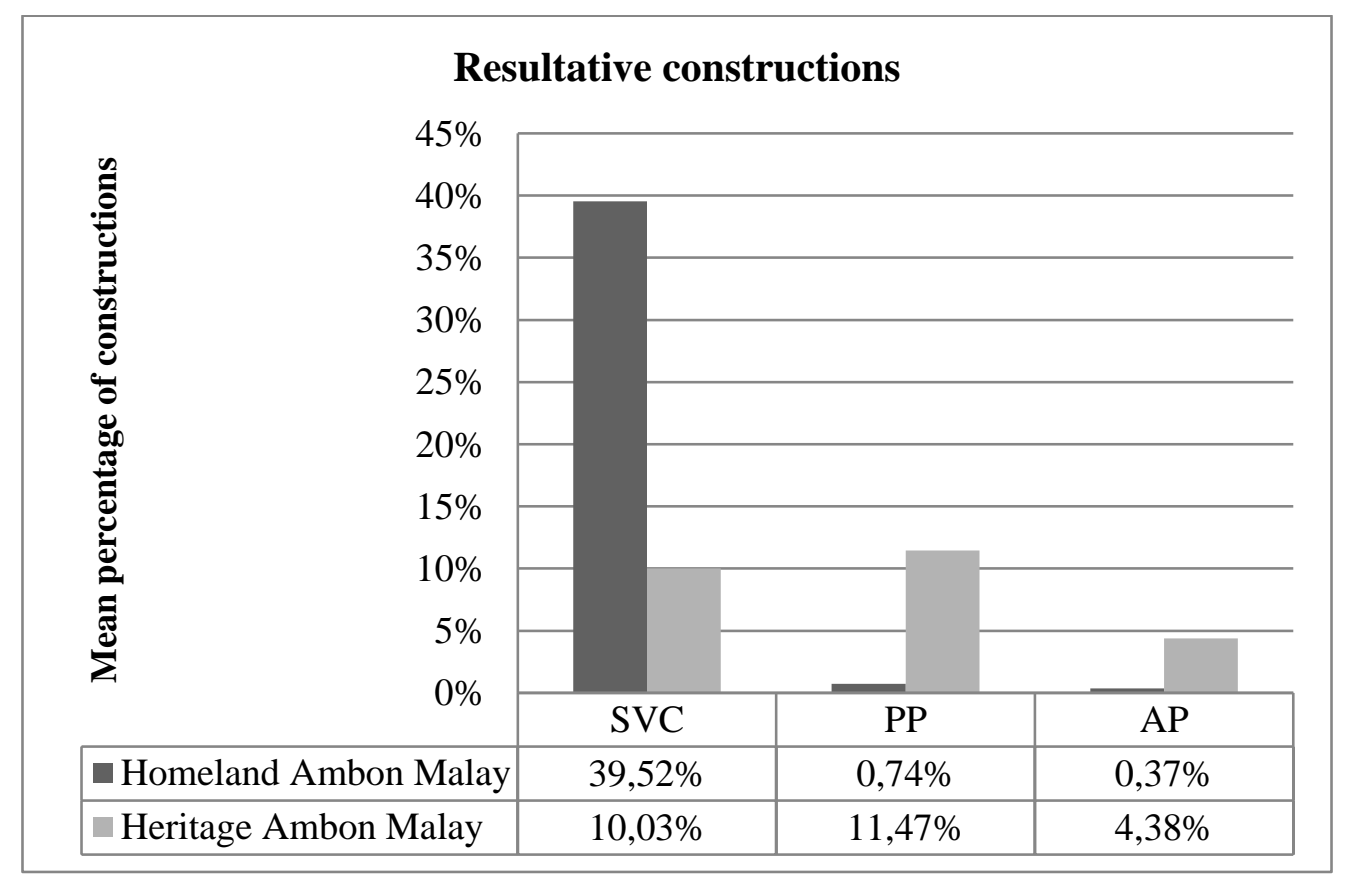

Figure 2. Use of resultative constructions among homeland Ambon Malay and heritage Ambon Malay speakers. ${ }^{4}$

\footnotetext{
${ }^{3}$ The dataset for this study are six short video-clips elicited via the video-clip description task.

${ }^{4}$ The percentages do not reach $100 \%$ because two other constructions are attested, namely the 'Two-predicate' and the 'unspecified result' (Moro, 2016). For the sake of clarity, these constructions have been omitted, as they do not pertain to the discussion here.
} 
The pre-nominal order for the demonstrative itu and the numeral satu 'one'. Ambon Malay allows an alternation between two word-order patterns: demonstratives and numerals can precede (DEM-N, NUM-N) or follow the noun (N-DEM, N-NUM). In the description of the 14 videos, homeland speakers have a strong preference for the post-nominal order, both in the case of the distal demonstrative itu 'D.DIST' and the numeral satu 'one'. On the other hand, heritage speakers prefer the pattern shared by Dutch, which only allows the pre-nominal order. In the case of the distal demonstrative itu 'D.DIST', heritage speakers show a neat preference for the DEM-N order (59.17\%); in the case of the numeral satu 'one', the trend is less neat but there is an increase in the frequency of NUM-N order (43.24\%). The data are summarized in Figure 3.

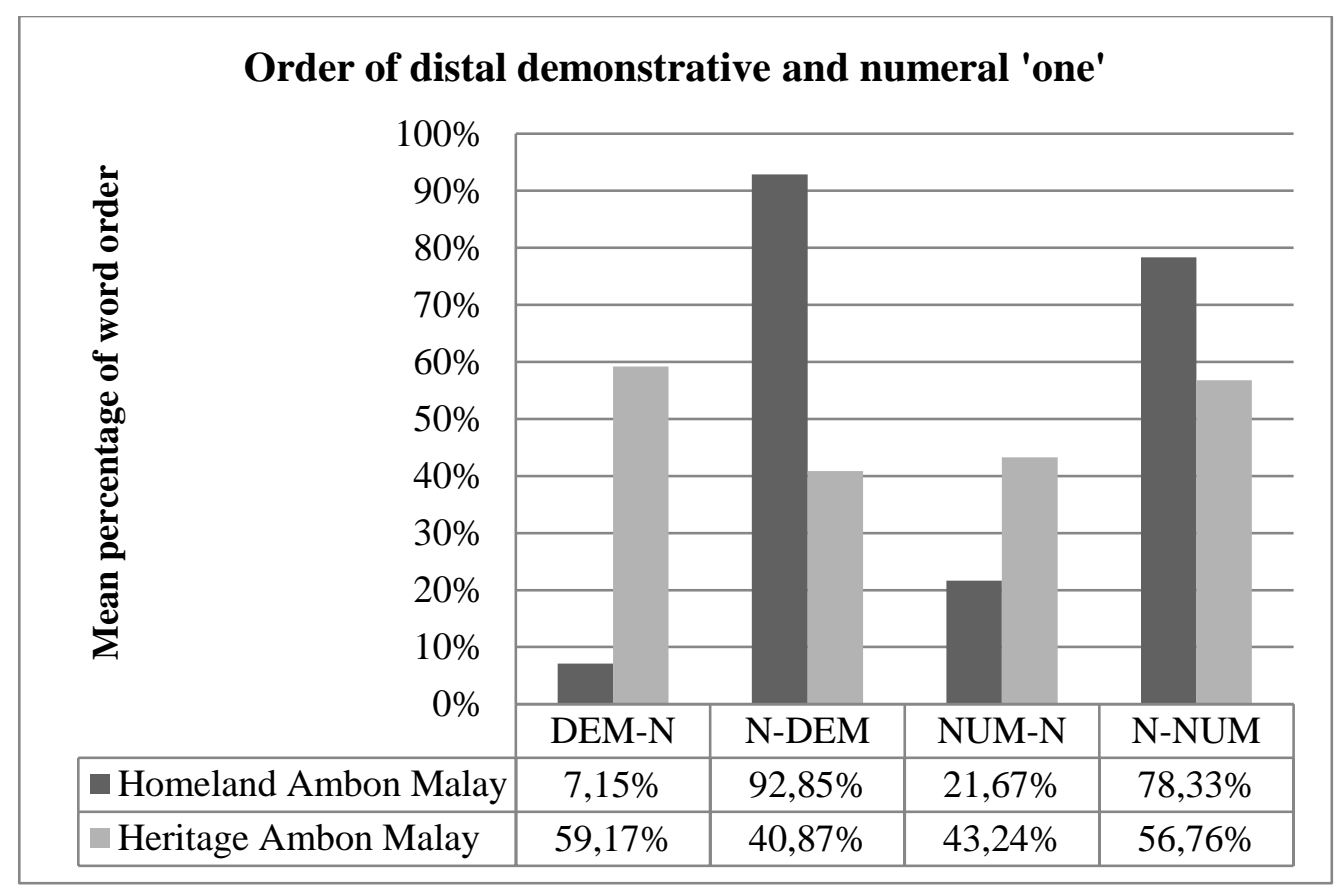

Figure 3. Order of the distal demonstrative itu and the numeral satu 'one' with respect to the noun in homeland Ambon Malay and heritage Ambon Malay speakers.

To sum up, heritage speakers tend to prefer the Dutch-like structure over the typical AmbonMalay structure, even when the former is only marginal in the homeland variety. These changes are on-going, and some speakers are more innovative than others. The following section shows that social-psychological factors can (partially) account for the variation among heritage speakers.

\section{Analysis: the role of social-psychological factors}

This section tests the effect of social-psychological factors on the use of Dutch-like structures. Based on previous research, the following six social-psychological factors were tested: onset of Dutch bilingualism, parental language input, generation, place where the speaker grew up, place 
where the speaker lives, and attitude (as shown in Tables 2 above). Here place where the speaker lives is taken as an indication of social network. Note that some of these factors are correlated: onset of Dutch bilingualism strongly correlates with parental language input $(r(32)=.866$, $p<.001)$, and also with place where the speaker grew up $(r(32)=.673, p<.001)$. In fact, sequential bilinguals are mostly individuals who grew up in households in Moluccan camps, where Ambon Malay was the main language spoken. Due to this correlation, the factors parental language input and place where the speaker grew up were excluded from the analysis.

Following common practices in variationist sociolinguistics, the effects of socialpsychological factors on speakers' performance were assessed using a multivariate general linear model (in SPSS). Given the small sample size (only 32 speakers), we can only expect to find statistical significance for the strongest effects, and where we do not find a significant effect it may either be that there is no such effect or that it is too weak to surface in the current sample.

The results of the general linear model analysis are summarized in Table 3 and discussed below.

Table 3: Multivariate general linear model (Sig.= statistical significance, $\mathrm{PES}=$ significant effect size, shaded cells indicate significant $\mathrm{p}$ values $\leq 0.05$ ).

\begin{tabular}{|c|c|c|c|c|c|c|c|c|c|c|c|c|c|c|}
\hline & \multicolumn{2}{|l|}{$a d a^{\mathrm{a}}$} & \multicolumn{2}{|c|}{$=n y a^{b}$} & \multicolumn{2}{|l|}{ DO $^{\mathrm{c}}$} & \multicolumn{2}{|l|}{$\mathbf{P P}^{\mathbf{d}}$} & \multicolumn{2}{|l|}{$\mathbf{A P} \mathbf{P}^{\mathbf{e}}$} & \multicolumn{2}{|l|}{$i t u^{\mathrm{f}}$} & \multicolumn{2}{|l|}{$s a t u^{g}$} \\
\hline & Sig. & PES & Sig. & PES & Sig. & PES & Sig. & PES & Sig. & PES & Sig. & PES & Sig. & PES \\
\hline Generation & .482 & .099 & .963 & .005 & .497 & .095 & .762 & .038 & .670 & .056 & .218 & 196 & 217 & .196 \\
\hline Place Live & .536 & .028 & .002 & .518 & .006 & .429 & 660 & .014 & .782 & .006 & .007 & .412 & .752 & .007 \\
\hline Onset Dutch & .605 & .020 & .008 & .405 & .026 & .306 & .952 & .000 & .282 & .082 & .909 & .001 & .229 & .102 \\
\hline Attitude & 264 & .088 & .820 & .004 & .033 & .286 & .129 & .157 & .099 & .183 & .896 & .001 & .283 & .082 \\
\hline $\begin{array}{l}\text { Place Live* } \\
\text { Onset Dutch }\end{array}$ & .682 & .012 & .000 & .634 & .002 & .510 & .051 & .245 & .122 & .163 & .110 & .172 & .302 & .076 \\
\hline $\begin{array}{l}\text { Place Live* } \\
\text { Generation }\end{array}$ & .566 & .024 & .030 & .294 & .048 & .251 & .796 & .005 & .871 & .002 & .090 & .192 & .878 & .002 \\
\hline $\begin{array}{l}\text { Place Live* } \\
\text { Attitude }\end{array}$ & .691 & .012 & .657 & .015 & .151 & .142 & .266 & .088 & .724 & .009 & .921 & .001 & .665 & .014 \\
\hline $\begin{array}{l}\text { Onset Dutch } \\
* \text { Attitude }\end{array}$ & .326 & .069 & .918 & .001 & .948 & .000 & .090 & .192 & .036 & .278 & .974 & .000 & .219 & .106 \\
\hline $\begin{array}{l}\text { Generation* } \\
\text { Onset Dutch }\end{array}$ & .854 & .002 & .346 & .064 & 1.00 & .000 & .770 & .006 & .197 & .116 & .324 & .069 & .326 & .069 \\
\hline $\begin{array}{l}\text { Generation* } \\
\text { Attitude }\end{array}$ & .656 & .058 & .979 & .003 & .807 & .030 & .610 & .068 & .423 & .116 & .255 & .178 & .222 & .194 \\
\hline
\end{tabular}

a. $\mathrm{R}$ Squared $=.480$ (Adjusted R Squared $=.034)$.

b. R Squared $=.777$ (Adjusted R Squared $=.586$ ).

c. R Squared $=.790$ (Adjusted R Squared $=.610)$.

d. R Squared $=.591$ (Adjusted R Squared $=.240)$.

e. R Squared $=.556$ (Adjusted R Squared $=.176$ ).

f. $\quad$ R Squared $=.588$ (Adjusted R Squared $=.236$ ).

g. R Squared $=.431$ (Adjusted R Squared $=-.057$ ) 
The general linear model analysis indicates that generation is not a predictor of Dutch-like feature use, as it does not play a role for any of the features. The place where the speaker lives has a significant effect for the features =nya 'DEF' $(p=.002)$, DO constructions $(p=.006)$, and pre-nominal itu 'D.DIST' ( $p=.007)$, such that heritage speakers living outside a Moluccan ward use these Dutch-like features more frequently. Onset of Dutch bilingualism has a significant effect for =nya 'DEF' $(p=.008)$ and DO constructions $(p=.026)$, such that sequential bilinguals use these Dutch-like features more frequently. Attitude has a significant effect only for DO constructions $(p=.033)$, such that speakers with a mild positive attitude use this Dutch-like feature more often than speakers with a strongly positive attitude. The interaction between place where the speaker lives and onset of Dutch bilingualism has a significant effect for the features $=n y a$ 'DEF' $(p<.001)$ and DO constructions $(p=.002)$, and a trend toward significance for PP constructions $(p=.051)$, such that sequential bilinguals living outside a Moluccan ward have the highest rate of these three Dutch-like features. The interaction between place where the speaker lives and generation also has a significant effect for the features $=n y a$ 'DEF' $(p=.030)$ and DO constructions ( $p=.048$ ), and a trend toward significance also for pre-nominal itu 'D.DIST' ( $p=$ .090 ), such that speakers of the second generation and of the generation 2.5 living outside a Moluccan ward are the most innovative. Finally, the interaction of onset of Dutch bilingualism and attitude has a significant effect for the use of AP constructions $(p=.002)$, and a trend toward significance for PP constructions $(p=.090)$, such that simultaneous bilinguals with only a mild positive attitude are the most innovative.

The general linear model has shown that the place where the speaker lives is the best predictor of Dutch-like features, followed by onset of Dutch bilingualism and attitude. A Bonferroni posthoc test was performed after any significant main effect. The results are summarized in Table 4 and discussed below.

Table 4: Mean of Dutch-like features in different populations of heritage speakers $(* p<.05$; $* * p<.001)$.

\begin{tabular}{lllllll}
\hline & Place Live & mean & Onset Dutch & mean & Attitude & mean \\
\hline ada 'EXIST' & outside Moluccan ward & .144 & sequential bilingual & .092 & mild positive & .124 \\
\cline { 2 - 7 } & inside Moluccan ward & .084 & simultaneous bilingual & .107 & strongly positive & .077 \\
\hline =nya 'DEF' & outside Moluccan ward & $.234^{* *}$ & sequential bilingual & $.209 *$ & mild positive & .145 \\
& inside Moluccan ward & .076 & simultaneous bilingual & .087 & strongly positive & .101 \\
\hline DO & outside Moluccan ward & $.219 * *$ & sequential bilingual & .150 & mild positive & $.159^{* *}$ \\
\hline inside Moluccan ward & .027 & simultaneous bilingual & .057 & strongly positive & $2.637 \mathrm{E}-16$ \\
\hline AP & outside Moluccan ward & .024 & sequential bilingual & .098 & mild positive & .030 \\
\hline PP & inside Moluccan ward & .056 & simultaneous bilingual & .023 & strongly positive & .066 \\
\hline itu 'D.DIST' & outside Moluccan ward & .081 & sequential bilingual & .075 & mild positive & $.154 *$ \\
\cline { 2 - 8 } & inside Moluccan ward & .097 & simultaneous bilingual & .100 & strongly positive & .021 \\
\hline inside Moluccan ward & $.862 *$ & sequential bilingual & .541 & mild positive & .622 \\
\hline \multirow{2}{*}{ 'one' } & outside Moluccan ward & .340 & sequential bilingual & .171 & mild positive & .380 \\
\hline & inside Moluccan ward & .289 & simultaneous bilingual & .364 & strongly positive & .216 \\
\hline
\end{tabular}


Speakers living outside a Moluccan ward have a higher rate of Dutch-like features (except for AP and PP constructions) than speakers living inside a Moluccan ward. Similarly, speakers with only a mild positive attitude toward the heritage language have a higher rate of Dutch-like features (except for AP constructions) than speakers with a strongly positive attitude. As for onset of Dutch bilingualism, the trend is less clear; in the case of =nya 'DEF', DO and AP constructions, sequential bilinguals are more innovative, while for the remaining Dutch-like features, it is simultaneous bilinguals who are more innovative.

Three case studies. This section describes three case studies of Ambon Malay heritage speakers, discussing their socio-psychological profile and their linguistic performance with respect to the above-mentioned Dutch-like features, see the comparison in Table 5 below.

Table 5: Percentage of Dutch-like features in homeland speakers and in three heritage speakers.

\begin{tabular}{l|l|l|l|l}
\hline & $\begin{array}{l}\text { Homeland } \\
\text { mean } \%\end{array}$ & $\begin{array}{l}\text { Max (generation 2.5, } \\
\text { simultaneous bilingual, } \\
\text { lives in a city, mild } \\
\text { positive attitude) }\end{array}$ & $\begin{array}{l}\text { Tom }\left(2^{\text {nd }} \text { generation, }\right. \\
\text { sequential bilingual, } \\
\text { lives in city, mild } \\
\text { positive attitude) }\end{array}$ & $\begin{array}{l}\text { Jan } 3^{\text {rd }} \text { generation, } \\
\text { simultaneous bilingual, lives } \\
\text { in a Moluccan ward, } \\
\text { strongly positive attitude) }\end{array}$ \\
\hline $\boldsymbol{a d a}$ 'EXIST' & $3.4 \%$ & $19 \%$ & $19 \%$ & $9 \%$ \\
$=$ nya 'DEF' & $0.4 \%$ & $17 \%$ & $43 \%$ & $3 \%$ \\
DO & $0.7 \%$ & $50 \%$ & $50 \%$ & $0 \%$ \\
AP & $0.7 \%$ & $22 \%$ & $20 \%$ & $0 \%$ \\
PP & $0.3 \%$ & $0 \%$ & $10 \%$ & $10 \%$ \\
itu 'D.DIST' & $7.1 \%$ & $83 \%$ & $100 \%$ & $29 \%$ \\
satu 'One' & $21.6 \%$ & $100 \%$ & $0 \%$ & $11 \%$ \\
\hline
\end{tabular}

The first speaker is Max (a fictitious name), a 45 years old man who belongs to the 2.5 generation. He grew up as simultaneous bilingual in Amsterdam, where he still lives today. He has a positive attitude toward the heritage language but he is not committed to heritage language maintenance and has not transmitted it to his daughter. He married a Dutch woman of nonMoluccan origin. He reports having both Dutch and Moluccan friends, and to occasionally speak heritage Ambon Malay with some of them. The heritage Ambon Malay he speaks presents a high rate of all the Dutch-like features (except for AP constructions).

The second speaker is Tom (a fictitious name), a 59 years old man who belongs to the second generation. He grew up as sequential bilingual in a Moluccan camp, but nowadays he lives in a city (outside any Moluccan ward). He is married to a Dutch woman of non-Moluccan origin. His attitude toward Ambon Malay is positive, but he thinks that the heritage language is not important, it becomes important only if one wants to move back to the Moluccas. The heritage Ambon Malay he speaks presents a high rate of all the Dutch-like features (except for pre-nominal satu 'one'.

The third speaker is Jan (a fictitious name), a 27 years old man who belongs to the third generation. He grew up as simultaneous bilingual in a Moluccan ward, where he still lives today. He has a very positive attitude toward the heritage language; he married a Dutch woman of Moluccan origin who also grew up in a Moluccan ward, and they are transmitting the heritage 
language to their daughter. He speaks Ambon Malay to his wife, and to his grandparents, who raised him. He reports feeling proud to be able to speak Ambon Malay. The heritage Ambon Malay he speaks is very homeland-like, with a low rate or absence of the above-mentioned Dutch-like features.

To conclude, the case studies show that generation does not play a role, as the speaker of the third generation, Jan, is the most conservative. Onset of Dutch bilingualism does not have a strong influence, because Max, a simultaneous bilingual, and Tom, a sequential bilingual, are both innovative. The place where the speaker lives and attitude seem to make a difference, Jan, who lives in a Moluccan ward and has strongly positive attitude toward the heritage language, speaks the variety less influenced by Dutch.

\section{Discussion}

The previous section tested the association between social-psychological factors and frequency of Dutch-like features to answer the question: Can social-psychological factors account for the different frequency of Dutch-like structures among heritage speakers? The factors place where the speaker lives, onset of Dutch bilingualism, and attitude all have a significant effect on the frequency of Dutch-like features among heritage Ambon Malay speakers. The place where the speaker lives and attitude have the expected effect, namely speakers living inside a Moluccan ward and with a strongly positive attitude are more conservative, while speakers living in a city (outside a Moluccan ward) and with only a mild positive attitude are the most innovative. Contrarily, onset of Dutch bilingualism does not have a clear effect. For some of the variables, it is sequential bilinguals who are more innovative, while following the literature, we would expect them to be more conservative, as they have been exposed solely to Ambon Malay during the first years of childhood. The first issue that this section addresses is, then, why onset of Dutch bilingualism does not have a straightforward effect in the shaping of heritage Ambon Malay grammar.

We have seen that, in some cases, sequential bilinguals show a higher rate of innovation than simultaneous bilinguals, and that second generation speakers seem more innovative than third generation ones. This apparently counterintuitive finding is actually in line with the observation of Schmid (2011), namely that language change may be found among speakers who frequently use their L1 and L2 alongside each other. Now, it is plausible to assume that, having received considerable Ambon Malay input in childhood, sequential bilinguals and second generation speakers are more confident about their linguistic skills in the heritage language, and thus use the language more frequently than the other speakers. The frequent use of the dominant and the heritage languages alongside each other creates the conditions for cross-linguistic influence. Thus, if high exposure in childhood translates into relatively frequent use in adulthood, then the language of sequential bilinguals can indeed show 'accelerated signs of contact induced change'.

Another issue related to onset of Dutch bilingualism is the nature of the linguistic variables that are tested. The innovative features described in this study are rather different from the 
features described by Montrul (2008) and Unsworth et al. (2014). The phenomena investigated by these authors are errors in tense-aspect-mood inflection morphology or in the assignment of grammatical gender. For this type of phenomena, age of onset of bilingualism has proved to be an important factor predicting the incomplete acquisition of morphological marking (but cf. Kupisch, 2013). The phenomena described in this study are not errors in inflectional morphology, but rather changes in frequency between structures already present in Ambon Malay. Acquiring the form-meaning mapping of a particular construction, together with its frequency, pragmatics, and contexts of usage may be a process that continues well beyond the age of five. Hence, onset of Dutch bilingualism may not make a difference, because the innovative features of Ambon Malay are not acquired once and for all in childhood but are part of a gradient process of language acquisition that continues through the lifetime and is sustained by other intervening factors, such as the amount and the type of Ambon Malay speaking contacts an individual has. This observation supports the importance of social network, to which we now turn.

Social network, operationalized here as the place where the speaker lives, is by far the most important factor in the heritage Ambon Malay community. Heritage speakers living outside a Moluccan ward show the highest rate of Dutch-like features, whereas speakers living in a Moluccan ward retain homeland Malay-like features more firmly. This finding agrees well with previous studies on the immigrant Chinese community (Wei, 1994; Chau, 2011) in the U.K. and other studies on the Ambon Malay community (Huwaë, 1992; Veenman, 1994; Tahitu \& Lasomer, 2001), which found an association between social network and language proficiency and language maintenance. The most straightforward explanation for this association is that heritage speakers living outside a Moluccan ward have fewer chances to speak Ambon Malay compared to their peers living inside a Moluccas ward, so their heritage language shows signs of 'atrophy'. Since they are fully immersed in a Dutch-speaking environment, there are higher chances that, when they speak Ambon Malay, they will rely on Dutch-like structures.

Another reason why heritage speakers living in a city (outside a Moluccan ward) are more innovative is that they are more likely to be part of a social network of weak ties (Milroy \& Milroy, 1985). Thanks to their 'mobility' and the many acquaintances they have (weak ties), these individuals are more likely to be exposed to new (linguistic) information and to pass them on. The process of propagation of linguistic innovations has been described by Enfield (2003, p. 366) in the following way:

Some individual or individuals begin to habitually perform a new linguistic act, exposing those in their personal network to the idea, with the result that those who are exposed then replicate this performance (given sufficient motivation to do so), and in turn expose more people in their own social networks (as well as those who began the process in the first place, revalidating and encouraging the usage, and leading it to take further hold).

Thus, it is likely that Ambon Malay heritage speakers living in a city participate in several networks and interact with (at least some) individuals in Ambon Malay; when they move from one network to another, they may (more or less voluntarily) diffuse the innovations that they have 
picked up in these former interactions. Their language thus shows signs of accelerated change. The interaction between place where the speaker lives and onset of Dutch bilingualism indicates that, among the speakers living in a city, the most innovative are sequential bilinguals, who supposedly use their heritage language frequently. This finding agrees with the observation that in order to be an innovator, a speaker needs to use his/her (heritage) language (Schmid, 2011). As mentioned above, sequential bilinguals probably feel more comfortable speaking the heritage language than (some) simultaneous bilinguals and this leads them to use Ambon Malay and Dutch alongside each other frequently. The continuous and frequent switch from one language to the other is likely to increase the chances of cross-linguistic influence, eventually leading to a shift in favour of Dutch-like structures.

Finally, attitude also influences the frequency of Dutch-like features. Heritage speakers with a strongly positive attitude retain homeland Malay-like features, while heritage speakers with only a mild positive attitude use Dutch-like features more frequently. This finding is in line with those of previous studies reporting an association between attitude and language proficiency (Kondo, 1997; Noels, 2005). In my sample, all heritage speakers with a strongly positive attitude have transmitted the heritage language to their children or are planning to do so, all (but one) have a spouse of Moluccan origin, some of them have joint Moluccan political or cultural organizations, one visits the Moluccas almost every year, another one writes songs in Ambon Malay and has participated to a workshop on language revitalization. In these settings, heritage speakers are likely to interact with monolingual speakers of Ambon Malay, or with other heritage speakers but without code-switching. In other words, these setting are conducive to maintain a baseline variety of the heritage language, one without much Dutch influence.

\section{Conclusion}

Heritage Ambon Malay in the Netherlands has been found to diverge from the homeland variety spoken on Ambon, Indonesia, and to converge toward Dutch. Convergence is mainly instantiated by changes in frequency between two structures, in favour of the structure which is shared with Dutch (Dutch-like feature). This study investigated what social-psychological factors predict the use of Dutch-like features among heritage speakers of Ambon Malay. The place where the speaker lives, taken here as an indication of social network, strongly predicts the amount of innovation in the heritage language: individuals living outside Moluccan wards are the ground breakers in most of the changes. Onset of Dutch bilingualism does not always have the expected effect; in some cases, sequential bilinguals are subject to more cross-linguistic influence (higher rate of Dutch-like feature) than simultaneous bilinguals, because they frequently use the two languages alongside each other. Finally, speakers with a very positive attitude will create and exploit all opportunities they have to speak the heritage language, which has a beneficial effect on the maintenance of homeland Malay-like features in their heritage language. 


\section{References}

Aalberse, S. P., \& Moro, F. R. (2014). Stability in Chinese and Malay heritage languages as a source of divergence. In K. Braunmüller, S. Höder, \& K. Kühl (Eds.), Stability and divergence in language contact: Factors and mechanisms (pp. 141-162). Amsterdam and Philadelphia: John Benjamins.

Benmamoun, E., Montrul, S., \& Polinsky, M. (2013). Heritage languages and their speakers: Opportunities and challenges for linguistics. Theoretical Linguistics, 39(3-4), 129-181.

Chau, W. C. (2011). The Influence of Dutch on Cantonese in the Netherlands. Rural versus urban areas. Unpublished Thesis, Universiteit Leiden.

Colleman, T., \& Bernolet, S. (2012). Alternation biases in corpora vs. picture description experiments: DO-biased and PD-biased verbs in the Dutch dative alternation. In D. Divjak, \& S. T. Gries (Eds.), Frequency effects in language representation (pp. 87-125). Berlin and Boston: Walter de Gruyter.

Croft, W. (2000). Explaining language change: An evolutionary approach. Harlow, England: Pearson Education.

Enfield, N. J. (2003). Linguistic epidemiology: Semantics and grammar of language contact in Mainland Southeast Asia. London, UK: RoutledgeCurzon.

Hulsen, M. E. H. (2000). Language loss and language processing: Three generations of Dutch migrants in New Zealand. Unpublished doctoral dissertation, Radboud Universiteit Nijmegen. Retrieved from http://repository.ubn.ru.nl/handle/2066/18901.

Huwaë, R. (1992). Tweetaligheid in Wierden: het taalgebruik van jongeren uit een Molukse gemeenschap. Unpublished doctoral dissertation, Universiteit van Amsterdam.

Irizarri van Suchtelen, P. (2014). Maintained and acquired heritage Spanish in the Netherlands: The case of dative constructions. Applied Linguistics Review, 5(2), 375-400.

Johanson, L. (2013). Structural factors in Turkic language contacts. New York, NY: Routledge.

Kondo, K. (1997). Social-psychological factors affecting language maintenance: interviews with Shin Nisei university students. Linguistics and Education, 9, 369-408.

Kondo-Brown, K. (2001). Bilingual heritage students' language contact and motivation. Motivation and second language acquisition, 23, 433-459.

Kondo-Brown, K. (2003). Heritage language instruction for post-secondary students from immigrant backgrounds. Heritage Language Journal, 1(1), 1-25.

Kupisch, T. (2013). A new term for a better distinction? A view from the higher end of the proficiency scale. Theoretical Linguistics, 39(3-4), 203-214. 
Milroy, J., \& Milroy, L. (1985). Linguistic change, social network and speaker innovation. Journal of Linguistics, 21(2), 339-384.

Montrul, S. (2008). Incomplete acquisition in bilingualism. Re-examining the age factor. Amsterdam and Philadelphia: John Benjamins.

Moro, F. R. (2014). Resultative constructions in heritage Ambon Malay in the Netherlands. Linguistics in the Netherlands, 31(1), 78-92.

Moro, F. R. (2015). Modal categories in contact: the case of heritage Ambon Malay in the Netherlands. Heritage Language Journal, 12(3), 271-291.

Moro, F. R. (2016). Dynamics of Ambon Malay: comparing Ambon and the Netherlands. Utrecht, NL: LOT, Netherlands Graduate School. Retrieved from: http://www.lotpublications.nl/Documents/422_fulltext.pdf

Moro, F. R. (2017). Aspectual distinctions in Dutch-Ambon Malay bilingual heritage speakers. International Journal of Bilingualism, 21(2), 178-193.

Moro, F. R., \& Klamer, M. (2015). Give-constructions in heritage Ambon Malay in the Netherlands. Journal of Language Contact, 8(2), 263-298.

Moro, F. R., \& Irizarri van Suchtelen, P. (2017). Dominant language transfer in heritage languages: Redefining the 'structural', and the 'transfer' in 'structural transfer'. In H. Peukert, \& I. Gogolin (Eds.), Dynamics of Linguistic Diversity (pp. 143-162). Amsterdam and Philadelphia: John Benjamins.

Muysken, P. C. (2010). Scenarios for Language Contact. In R. Hickey (Ed.), The handbook of language contact (pp. 265-281). Malden, MA: Wiley-Blackwell.

Noels, K. (2005). Orientations to learning German: Heritage language learning and motivational substrates. Canadian Modern Language Review, 62(2), 285-312.

Polinsky, M., \& Kagan, O. (2007). Heritage languages: In the 'wild' and in the classroom. Language and Linguistics Compass, 1(5), 368-395.

Schmid, M. S. (2011). Contact x time: External factors and variability in L1 attrition. In M. S. Schmid, \& W. Lowie (Eds.), Modeling bilingualism: From structure to chaos. In honor of Kees de Bot (pp. 155-176). Amsterdam and Philadelphia: John Benjamins.

Silva-Corvalán, C. (1994). Language contact and change: Spanish in Los Angeles. Oxford, UK: Clarendon Press.

Tahitu, B. (1989). Melaju Sini. Het Maleis van Molukse jongeren in Nederland. Unpublished doctoral dissertation, Universiteit Leiden. 
Tahitu, B., \& Lasomer, X. (2001). Moluks-Maleis. In G. Extra, \& J. J. de Ruiter (Eds.), Babylon aan de Noordzee: Nieuwe talen in Nederland (pp. 153-174). Amsterdam, The Netherlands: Bulaaq.

Unsworth, S., Argyri, F., Cornips, L., Hulk, A., Sorace, A., \& Tsimpli, I. (2014). The role of age of onset and input in early child bilingualism in Greek and Dutch. Applied Psycholinguistics, 35(4), 765-805.

Veenman, J. (1994). The social integration of Moluccans. Rotterdam, The Netherlands: Koninklijke Vermande/ ISEO.

Vermeulen, H., \& Penninx, R. (2000). Immigrant integration: The Dutch case. Amsterdam, The Netherlands: Het Spinhuis.

Wei, L. (1994). Three generations, two languages, one family: Language choice and language shift in a Chinese community in Britain. Clevedon, UK: Multilingual Matters.

Wei, L., Milroy, L., \& Ching, P. S. (2000). A two-step sociolinguistic analysis of codeswitching and language choice: the example of a bilingual Chinese community in Britain. In L. Wei (Ed.), The bilingualism reader (pp. 188-209). London \& New York: Routledge. 